\title{
Identifications of the Factors Influencing the Operation of Storage Batteries
}

\author{
Rijarimanana Tiana Andriantsoa \\ Student, \\ Doctoral School in Science and Technology of Engineer and \\ Innovation \\ Polytechnic College of Antananarivo \\ Antananarivo, Madagascar
}

\begin{abstract}
In order to increase the energy efficiency of storage systems, in this article we present the factors influencing the way how the accumulators operate, particularly temperature and duration. For this purpose, modelling and simulation of its characteristics will be conducted, depending on the operating regime: in charge and discharge. This model has allowed us to show that depending on the type of use, the sizing and choice of batteries are not limited in terms of power and voltage sufficiency but also the conditions of use.
\end{abstract}

Keywords-Accumulators; Charge; Discharge; Temperature; Voltage

\section{INTRODUCTION}

Renewable energy sources for electricity production have several assets to meet the current energy challenge. However, the produced energy has certain shortcomings such as the intermittency of the sources, the gap between production and consumption. To temporarily overcome this problem, it is necessary to use energy storage means such as storage batteries. However, in order to ensure its security on the one hand and to ensure a continuous supply of the installation on the other hand, it is necessary to identify the factors influencing its operation. For this, a modeling and a simulation of its characteristics were presented.

\section{MODELING}

\section{A. Presentation}

A battery is formed of several associated accumulator elements which is an electrochemical generator designed to be recharged. It is capable of converting electrical energy into chemical energy and vice versa. These operations are respectively called charge and discharge. It consists of two electrodes, electrolyte and separators. There are several types of storage batteries in the literature depending on their manufacturing technology. In our study, we choose the types of lead/acid batteries because of their relatively low cost and wide availability.

\section{B. Modelling}

Although there are several models in the literature, we have chosen the CIEMAT models whose advantage is to be said "universal"; there is thus no experimental identification of empirical parameters necessary for the use of other commonly used models. [1]-[2]-[3]-[4]

This model is based on the electrical diagram of Figure 1; a battery can be described by two elements the characteristics of which depend on a number of parameters: a voltage source and

\author{
Yvon Andrianaharison \\ Professor, \\ Doctoral school in science and Technology of engineer and \\ Innovation \\ Polytechnic College of Antananarivo \\ Antananarivo, Madagascar
}

its internal resistance. This model has the advantage of being independent of the type of batteries.



Fig. 1. Equivalent electrical diagram of $\mathrm{N}_{\text {bat }}$ battery elements in series.

By applying Kirchhoff's Voltage Law, we have:

$$
\mathrm{U}=\mathrm{N}_{\text {bat }} \times \mathrm{E}+\mathrm{N}_{\text {bat }} \times \mathrm{I} \times \mathrm{R}_{\mathrm{i}}
$$

Where $\mathrm{U}$ and I are respectively the voltage and current, $\mathrm{E}$ is the electromotive force, $\mathrm{R}_{\mathrm{i}}$ is the internal resistance of an element and $\mathrm{N}_{\text {bat }}$ is the Number of batteries in series.

- Current Model:

$$
I=\frac{n E}{R} \exp \left(\frac{-t}{R_{C}}\right)
$$

Where $\mathrm{R}$ is the internal resistance, $\mathrm{R}_{\mathrm{C}}$ is the load resistance, $\mathrm{t}$ is the time and $\mathrm{n}$ is the cell number.

\section{Capacity Model}

The capacity of an accumulator depends on the reference current $\mathrm{I}_{\text {ref }}$, corresponding to the operating speed $\mathrm{C}_{\text {ref }}$ and its heating $\Delta \mathrm{T}$ relative to an ambient temperature equal to $25^{\circ} \mathrm{C}$.

$$
\begin{gathered}
C=C_{\text {ref }} \frac{1,67}{1+0,67\left(\frac{I}{I_{\text {ref }}}\right)^{0,9}(1+0,005 \Delta T)} \\
\text { Nominal capacity model FORMULA IEC 254-1: } \\
\quad C=C_{\text {ref }}\left(1+0.008\left(T-T_{\text {ref }}\right)\right)
\end{gathered}
$$

Where $\mathrm{T}$ and $\mathrm{T}_{\text {ref }}$ are respectively the temperature and reference temperature. 
- Model of the state of discharge:

$$
E D=1-\frac{Q_{d}}{C}
$$

Where ED is the state of discharge, $\mathrm{Q}_{\mathrm{d}}$ is the amount of charge missing from the battery.

- $\quad$ Model of the charging voltage:

The expression of the voltage across the battery in charge is described by two equations, one before the occurrence of gassing phenomenon and the other after (overload). But in our study, we will always work below the gassing voltage. Thus, we have:

$$
\begin{gathered}
U_{c}=n(2+0,16 E D)+n \frac{l}{C_{r e f}}\left(\frac{6}{1+l^{0,86}}+\frac{0,48}{(1-E D)^{1,2}}+0,036\right)(1-0,025 \Delta T) \\
E C=1-E D
\end{gathered}
$$

Where EC is the state of charge

$$
\begin{gathered}
\text { - Model of discharge voltage: } \\
V_{d}=n(1,965+0,12 E D)-n \frac{l}{C_{r e f}}\left(\frac{4}{1+I^{1,9}}+\frac{0,27}{(E D)^{1,5}}+0,02\right)(1-0,007 \Delta T)
\end{gathered}
$$

- Model of saturation voltage at rest:

$$
U_{c c}=n\left(2,45+2,011 \ln \left(1+\frac{I}{C_{r e f}}\right)\right)(1-0,02 \Delta T)
$$

- Model of gassing voltage:

$$
U_{g}=n\left(2,24+1,97 \ln \left(1+\frac{I}{C_{\text {ref }}}\right)\right)(1-0,02 \Delta T)
$$

- Model of transfer resistance:

$$
R_{t}=\frac{-t}{\operatorname{cln}\left(\frac{E D C-1}{n E}\right)}
$$

Where EDC is the state of charge or discharge and $\mathrm{C}$ is the capacity.

\section{SIMULATION OF CHARACTERISTICS VARIATION}

The simulations under MATLAB provide us with the following results:

\section{A. Influence of temperature}

- $\quad$ On the capacity



Fig. 2. Influence of temperature on the capacity, $\mathrm{C}=\mathrm{f}(\mathrm{I})$



Fig. 3. Influence of temperature on the capacity, $\mathrm{C}=\mathrm{f}(\mathrm{T})$

\section{- $\quad$ On the state of the batteries}

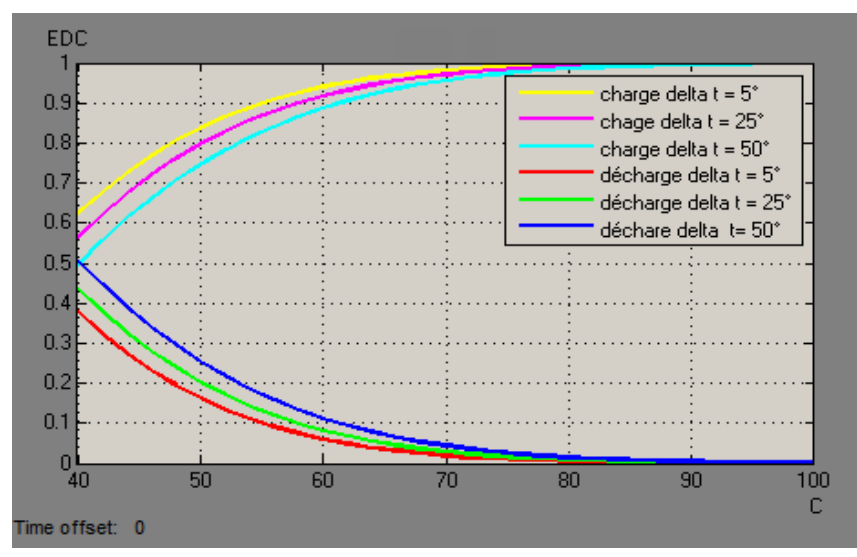

Fig. 4. Influence of the temperature on the state of charge and discharge of the batteries $\mathrm{EDC}=\mathrm{f}(\mathrm{C})$

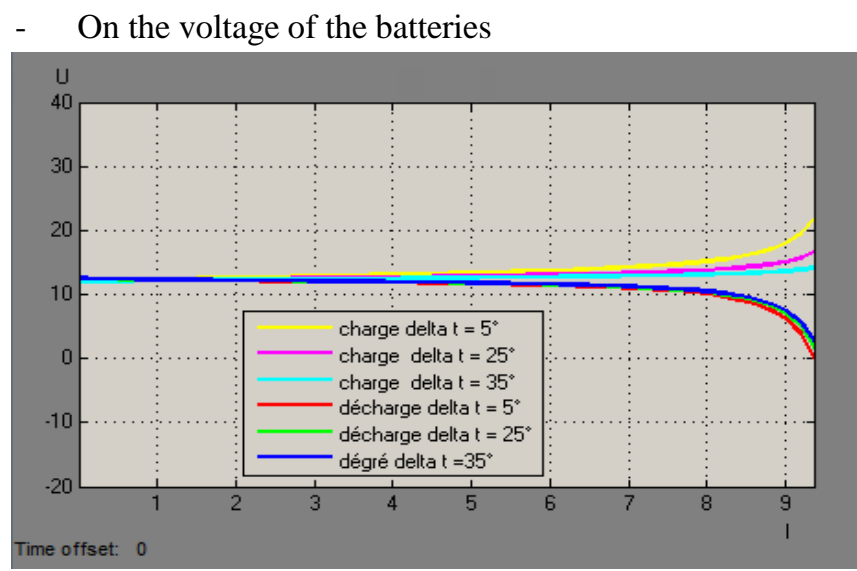

Fig. 5. Influence of the temperature on the voltage ((charge / discharge) $U=f$ (I) 


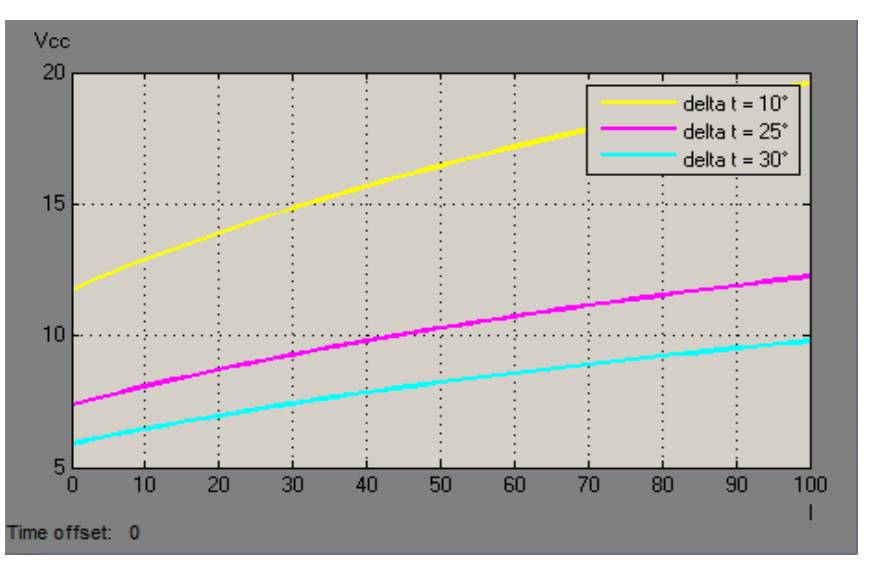

Fig. 6. Influence of the temperature on the voltage Saturation $\mathrm{U}_{\mathrm{cc}}=\mathrm{f}(\mathrm{I})$

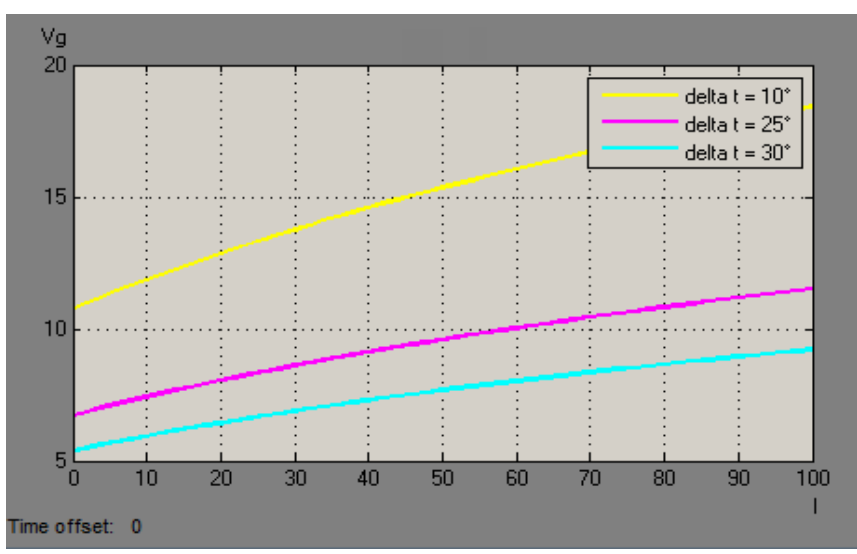

Fig. 7. Voltage of gassingUg $=\mathrm{f}(\mathrm{I})$

\section{B. Influence of time}

- Battery status

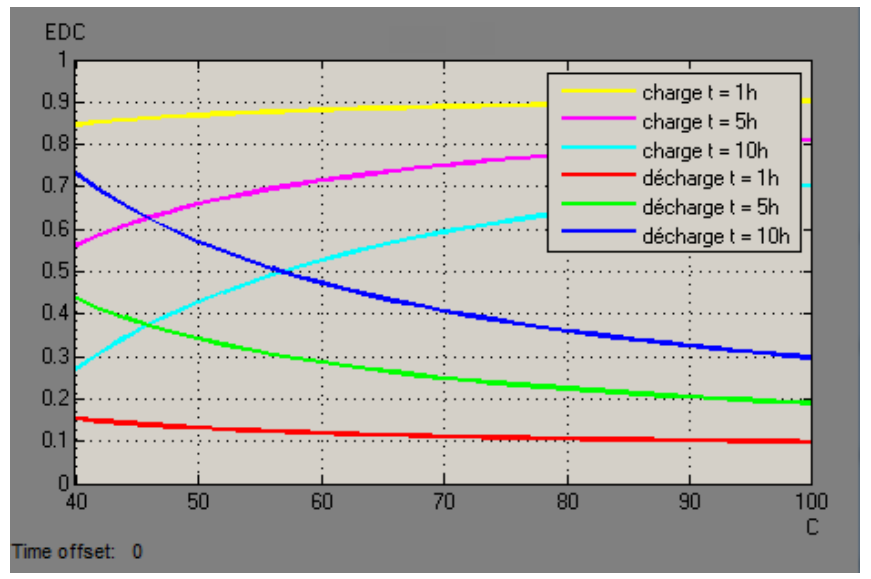

Fig. 8. Influence of time on the state of charge and discharge of a battery $\mathrm{EDC}=\mathrm{f}(\mathrm{C})$



Fig. 9. Influence of time on the voltage (charge / discharge) $\mathrm{U}=\mathrm{f}$ (I)

\section{Resistance of the battery}

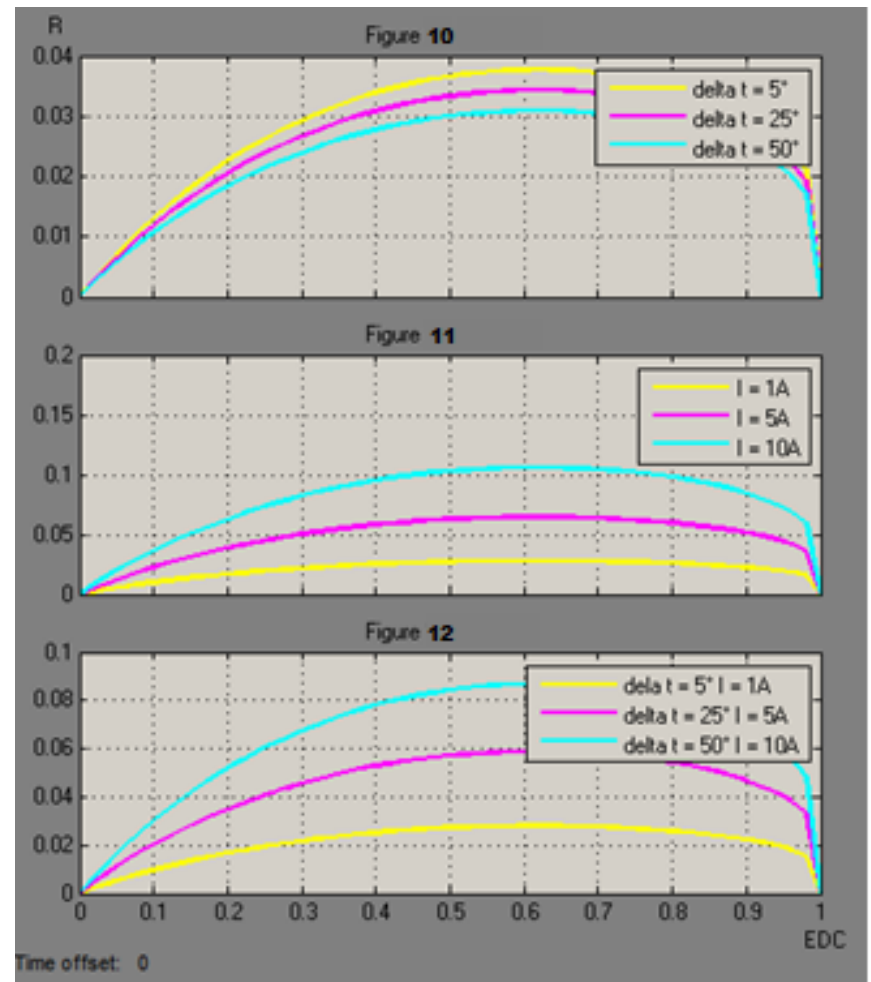

Fig. 10, Fig. 11, Fig. 12. Battery Resistance (constant current and fixed temperatures / constant temperature and fixed currents / fixed current and temperature) $\mathrm{R}=\mathrm{f}(\mathrm{EDC})$

\section{INTERPRETATION}

Figure 2 and Figure 3 shows that the increase in temperature is accompanied by a moderate increase with that of the storage capacity of the batteries. This increase reveals that the exchange of electrical energy with the outside is always accompanied by a rise in temperature.

In Figure 4, the influence of temperature on the capacity is still justified because when the temperature decreases, the state of charge increases in the case of loading; on the other,the increase of temperature is accompanied by the increase of the state of discharge in the case of unloading. 
In the same way as the state of charge for Figure 5; the temperature influences the voltage while the increase of voltage is accompanied by a decrease of temperature in charging mode, whereas increasing the voltage is accompanied by an increase in the temperature in discharge mode.

It is also as well that the temperature also influences the saturation voltage which is the maximum voltage of use in charge and discharge. Figure 6 shows us that the more the temperature decreases, the more the voltage increases.

Gassing voltage or gasification voltage, above a limit voltage, the electrolysis of the water becomes too fast. Therefore, there is release of hydrogen and oxygen. For the result of Figure 7, it still demonstrates in the same way the influence of temperature on the voltage.

Figure 8 shows us that the duration is inversely proportional in the case of charge and discharge. The shorter the charging time, the more the charge state increases; conversely, the shorter the discharge time, the lower the state of discharge becomes.

The influence of the duration is in the same way as that of the state of charge in Figure 9.

Figure 10, Figure 11, Figure 12: Depending on the operating regime, the internal resistance varies, i.e., it follows the same variation of the current; but under the influence of temperature, it varies inversely. In the case where there is a simultaneous variation of temperature and current; only the current influences most the variation of the internal resistance.

\section{CONCLUSION}

This model has allowed us to show that depending on the type of use, the sizing and choice of batteries are not limited in terms of power and voltage sufficiency but also the conditions of use, particularly duration and temperature. The evaluation of the influence of these factors makes it possible to derive results on the internal physical behaviour of the storage system. All this is to minimize risks, to cushion the cost, and to improve the operation of an entire installation.

\section{REFERENCES}

[1] Christian DUMBS, "Development of tools for the analysis of photovoltaic-diesel hybrid systems", thesis of the Ecole des Mines de Paris, defended on December 20, 1999.

[2] I MARIE-JOSEPH, "Diagnostic methodology applied to the preventive maintenance of electricity production units in isolated sites", progress report of thesis work 2 for ADEME.

[3] C. TROUSSEAU, "Validation of simulation tools for photovoltaic systems based on experimental measurements: application of lead / acid accumulators", working report, energy center, Ecole des Mines de Paris, 1997.

[4] T. Degner, H Gabler and A. Stöcklein, 'A Model for the Ageing of Lead/Acid Batteries in PV Systems', 12th European Photovoltaic Solar Energy Conference, Amsterdam, pp. 422-426, 1994.

[5] HG. Beyer, M. Bohlen and J. Schumacher, 'Including Battery Life Time Modeling in Sizing Procedures for Stand Alone PV-Systems', 14th European Photovoltaic Solar Energy Conference, Barcelona, Spain, pp. 1086-1089, 1997.

[6] T. Degner, H Gabler and A. Stöcklein, 'A Model for the Ageing of Lead/Acid Batteries in PV Systems', 12th European Photovoltaic Solar Energy Conference, Amsterdam, pp. 422-426, 1994. 